\title{
Integrating Cybercartography and Cybernetics in the Circle of All Nations Indigenous mapping exemplar of William Commanda
}

\author{
Romola V. Thumbadoo \\ Carleton University, Canada-RomolaThumbadoo@cmail.carleton.ca
}

Keywords: Indigenous, spatial and temporal navigation, multidimensional Cybercartographic digital atlas mapping

\begin{abstract}
:
Tourist to Guide

Tourist: "Do you know where we are?" Guide: "No."

Tourist: "Then you are no good." Guide: "But I am not lost!"

Can foundational Indigenous thinking assert influence in this age of information and global dis-connection?
\end{abstract}

This paper will consider the multidimensional navigation of spatial and temporal interrelatedness in the Circle of All Nations Cybercartographic digital atlas mapping story and Cybernetic mapping journey animated by late Indigenous Elder William Commanda. It will examine his underlying linguistic and performative practice of Ginawaydaganuc; this is hypothesised as his foundational knowledge superstratum, comparable to inter-operability; however, while it encompasses the technological, goes beyond by integrating geocosmic and human dimensions. As such it challenges Cartesian dualities and dichotomization by breaking down barriers and building unifying relational bridges.

Finally, these ideas will be scrutinized for evidence of contemporary significance in the digital age, through the Cybercartographic atlas, constituted in locational textual and audio-visual digital media storytelling, and the Cybernetic Facebook social media platform, comprised of dynamic, fast-paced, interactive, information dissemination and knowledge generation, and a year of global live video conferences

\section{Acknowledgements}

I acknowledge the support and guidance of Professor D. R. Fraser Taylor, Director Geomatics and Cartographic Research Centre

\section{References}

Taylor, D. R. F., (Editor) Anonby, E., Murasugi, K. (Associate Editors). (2019) Further Developments in the Theory and Practice of Cybercartography: International Dimensions and Language Mapping, Elsevier, Amsterdam Taylor D. R. F. (2021). Mapping with Indigenous Peoples in Canada. Hess, J. (Ed.) Digital Mapping and Indigenous America. Routledge.93-108

Taylor, D. R. F. (2014). Some Recent Developments in the Theory and Practice of Cybercartography: Applications and Indigenous Mapping: Introduction, Chapter in (Taylor, D. R. F and Lauriault, T.P. (associate ed) Developments in the Theory and Practice of Cybercartography: Applications and Indigenous Mapping. Amsterdam: Elsevier, 1-13

Thumbadoo, R.V. (2018). Ginawaydaganuc and the Circle of All Nations: The Remarkable Environmental Legacy of Elder William Commanda PhD Thesis. Ottawa. Carleton University. https://curve.carleton.ca/aa4e3cbb-5b83- 464d8286-a901fcd77b06

Thumbadoo, R. V., Taylor, D. R. F. Circle of All Nations Digital Global Village - William Commanda's Indigenous Cybernetic Navigation into the Age of Information Technology 21CW2020: IEEE SSIT 3rd Conference on Norbert Wiener in the 21st Century 2021 